\title{
Síndrome de neoplasia endocrina múltiple tipo 2B. Ganglioneuromatosis intestinal difusa y carcinoma medular de tiroides
}

\section{Multiple endocrine neoplasia syndrome type 2B. Diffuse intestinal ganglioneuromatosis and medullary carcinoma of the thyroid}

María de la Luz Ruiz-Reyes, ${ }^{1}$ Pedro Mario Pasquel-García Velarde ${ }^{2}$

\section{RESUMEN CLÍNICO}

Niña de cinco años al ingreso al Instituto que a los seis meses tuvo distensión abdominal y estreñimiento; en la exploración física se encontró con facies tosca. Fue atendida en varios hospitales, en uno de ellos se le realizó una colostomía. A los cuatro años le practicaron: el cierre de la colostomía, resección de íleon terminal con ileostomía y mapeo intestinal. El estudio histopatológico reportó ganglioneuromatosis difusa. Posteriormente tuvo disfunción de la ileostomía y se llevó a cabo colectomía total e ileo-procto-anastomosis 14 meses después. En la valoración por los endocrinólogos se encontraron concentraciones séricas de calcitonina de $105 \mathrm{pg} / \mathrm{mL}$ (normal 0-30 pg/mL). En el ultrasonido de tiroides se identificaron dos nódulos: uno derecho de $3 \mathrm{~mm}$ y otro izquierdo de $2 \mathrm{~mm}$. Se practicó la tiroidectomía total.

\section{Hallazgos anatomopatológicos}

En el aspecto macroscópico inicialmente se estudiaron dos segmentos de íleon terminal de 6 y $4 \mathrm{~cm}$ de longitud mayor y menor, respectivamente. Los especímenes mostraron a la serosa sumamente engrosada y la pared indurada e irregular. El calibre de la luz estaba muy disminuido. El colon se recibió en dos segmentos que midieron, en conjunto, $34 \mathrm{~cm}$ de longitud. El aspecto era semejante al del intestino delgado.

Al microscopio, la lesión consiste en una proliferación muy prominente de troncos y plexos nerviosos que afecta todas las áreas del intestino explorado y diferentes partes de la pared. En las muestras de íleon
${ }^{1}$ Médica adscrita al servicio de Endocrinología.

${ }^{2}$ Médico adscrito al departamento de Anatomía patológica.

Instituto Nacional de Pediatría, Ciudad de México.

Recibido: 3 de diciembre 2018

Aceptado: 5 de diciembre 2018

Correspondencia Pedro Mario Pasquel-García Velarde dr.pasquel@gmail.com

Este artículo debe citarse como Ruiz-Reyes ML, Pasquel-García Velarde PM. Síndrome de neoplasia endocrina múltiple tipo 2B. Ganglioneuromatosis intestinal difusa y carcinoma medular de tiroides. Acta Pediatr Mex. 2019;40(1):28-31. 
terminal, apéndice cecal, colostomía y sigmoides se apreciaban cambios en la submucosa y en la pared muscular. En las muestras de ciego y colon transverso los cambios se localizaban, predominantemente, en los plexos mientéricos. Todos los cambios observados sirvieron de base para establecer el diagnóstico de ganglioneuromatosis difusa.

En la glándula tiroides se identificaron dos nódulos: uno en cada lóbulo, de $0.2 \mathrm{~cm}$ de diámetro, blanquecinos, de consistencia firme y debidamente circunscritos. Al estudio microscópico correspondieron a neoplasia maligna epitelial constituida por células de tamaño mediano, citoplasma claro o eosinófilo y con discreto pleomorfismo nuclear. Las células estaban dispuestas en grupos separados por una red capilar. En su mayor parte el tumor estaba debidamente limitado por el parénquima tiroideo vecino. La reacción de inmunohistoquímica para sinaptofisina resultó positiva, y con ello se corroboró su naturaleza neuroendocrina. Figuras 1-6

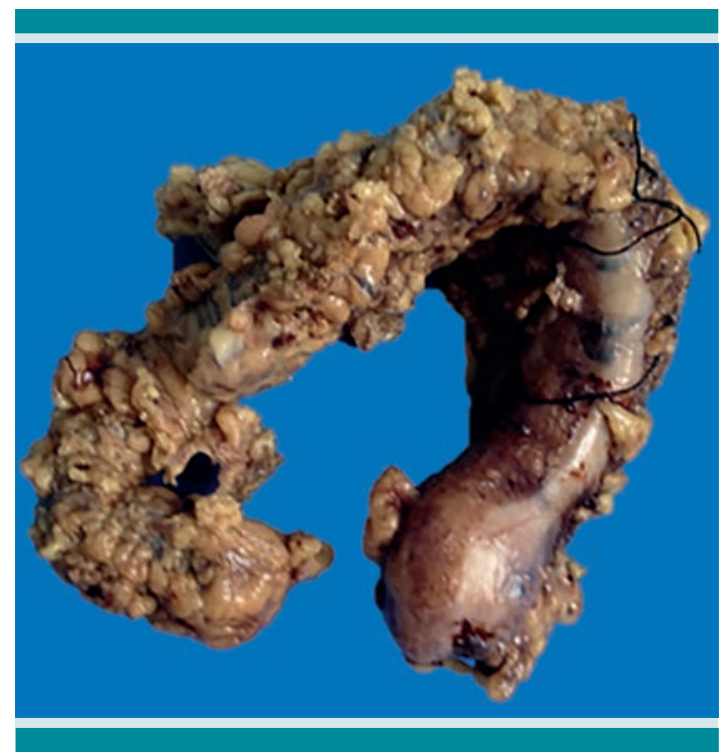

Figura 1. Espécimen de colectomía. El tejido adiposo de la serosa es abundante y de aspecto nodular irregular.

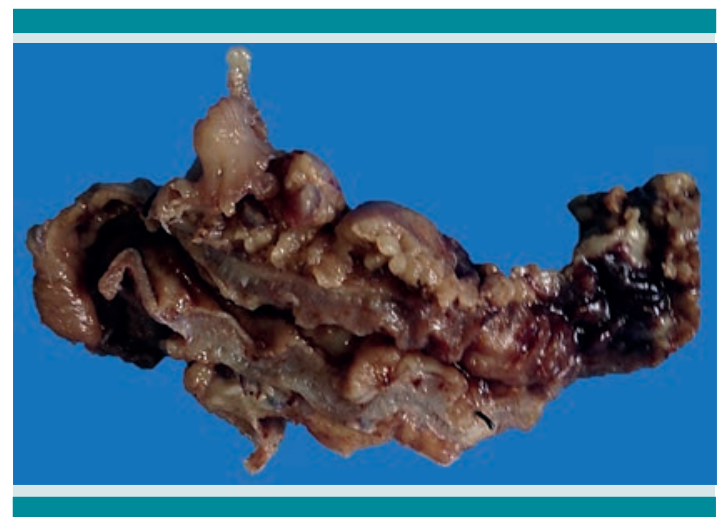

Figura 2. Segmento de intestino delgado al corte, con disminución del calibre de su luz y pared irregularmente engrosada.

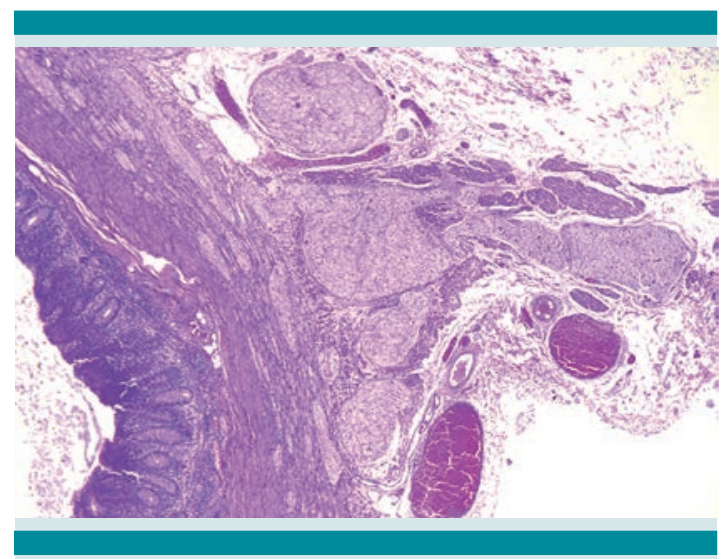

Figura 3. En la serosa y en la grasa pericolónica se observan nódulos de gran tamaño. Los plexos mientéricos se aprecian muy irregulares. A la izquierda se identifica mucosa colónica normal.

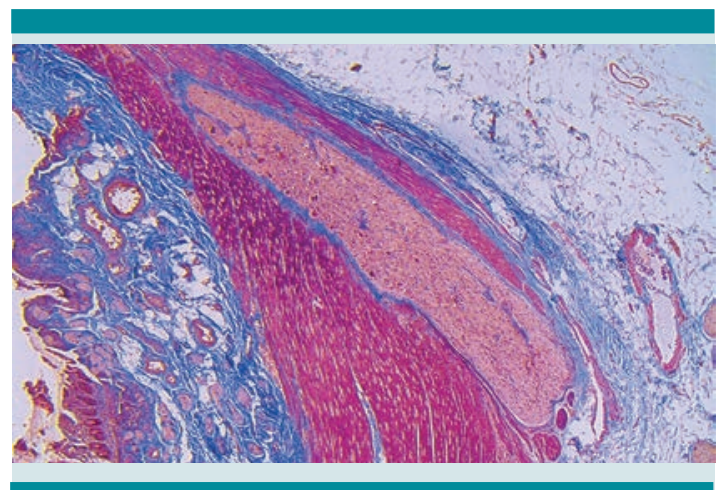

Figura 4. Con tinción de Masson se observa un cordón grueso que afecta a la muscular y serosa y tiene numerosas células ganglionares irregulares. 


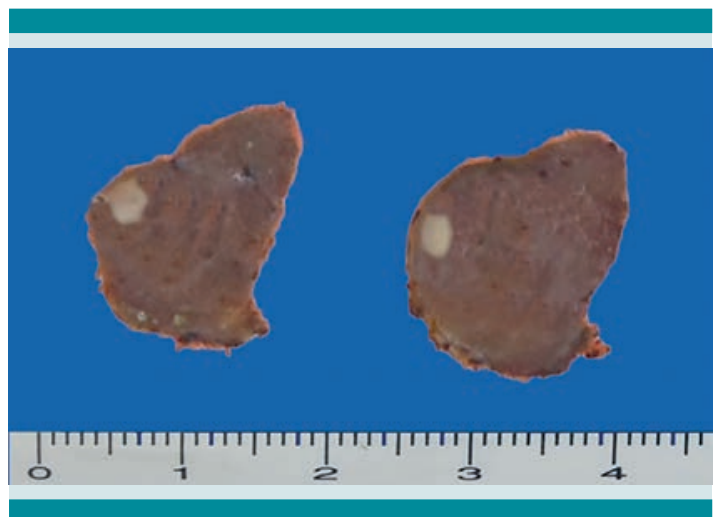

Figura 5. Ambos lóbulos tiroideos al corte. Cada uno muestra un nódulo tumoral de $0.2 \mathrm{~cm}$.

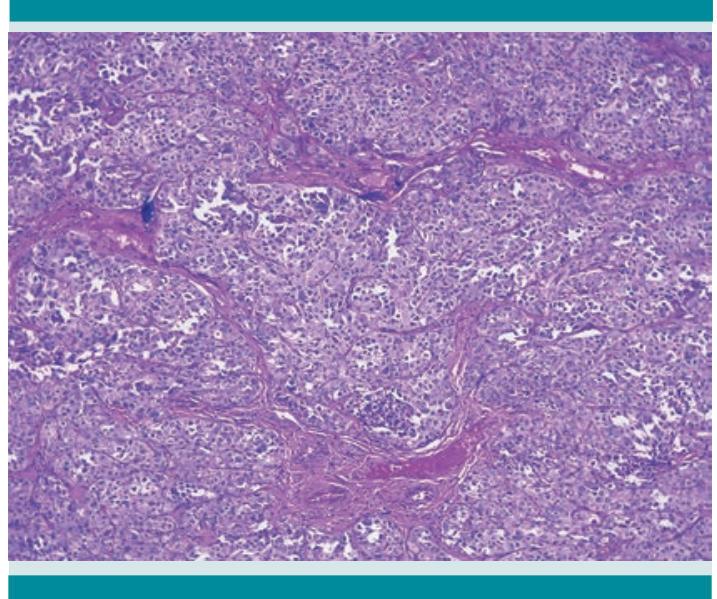

Figura 6. Aspecto microscópico de la neoplasia. Es evidente el patrón lobular y moderado pleomorfismo.

\section{Comentario clínico}

Este caso se refiere a una niña en el primer año de edad con desnutrición, talla baja, facies tosca, estreñimiento grave, crónico y antecedentes de oclusión intestinal. Se descartó hipotiroidismo, pero el estreñimiento crónico fue la manifestación clínica de una serie de padecimientos.

Requirió colostomía y se sospechó enfermedad de Hirschprung, que fue descartada a los 15 meses por biopsia que reportó displasia de células ganglionares. A los cuatro años se le tomaron nuevas biopsias que reportaron ganglioneuromatosis difusa, con lo que se estableció el diagnóstico de probable neoplasia endocrina múltiple tipo 2B (NEM 2B).

La neoplasia endocrina múltiple tipo $2 \mathrm{~B}$ es un síndrome de tumores endocrinos derivados embriológicamente de la cresta neural que, tempranamente, inicia con cáncer medular de tiroides en todos los casos y feocromocitoma en $50 \%$.

El cáncer medular de tiroides es una de las formas más agresivas de cáncer de tiroides porque no reacciona favorablemente a la quimioterapia ni a la radioterapia y es la principal causa de muerte en estos pacientes. El único tratamiento curativo es la tiroidectomía profiláctica lo antes posible e, idealmente, antes del primer año de vida en niños en riesgo, para evitar metástasis.

La apariencia física de estos pacientes es clásica y el desarrollo trascurre con hábito marfanoide (extremidades largas, hiperlaxitud, braquidactilia), neuromas en el interior de los párpados (que puede evertirlos), labios y lengua. El caso clínico aquí descrito ya tenía facies tosca, párpados evertidos y nódulos en la lengua desde los cuatro años.

Los neuromas también aparecen en todo el aparato gastrointestinal, circunstancia que origina la pérdida del tono muscular, con distensión, dilatación segmentaria y megacolon que se manifiestan con dolor abdominal, estreñimiento grave y obstrucción mucho antes de los síntomas tiroideos, como se refiere en el caso clínico motivo de esta comunicación.

El diagnóstico histológico de ganglioneuromatosis intestinal en niños con estreñimiento grave y crónico debe alertar a patólogos, cirujanos y pediatras porque traduce la existencia de neoplasia endocrina múltiple tipo 2B. 
La neoplasia endocrina múltiple tipo 2B se trasmite de manera autosómica dominante $y$, en la mayoría de los casos, son mutaciones de novo. Se origina por mutaciones en la línea germinal en el protoncogén RET (10q11.2), que codifica para el receptor transmembrana de tirosina cinasa, sobreactivándolo para ganar función. Existe una estrecha correlación entre el codón RET mutado y la agresividad. El 98\% de los pacientes con esta neoplasia tienen una mutación en el codón 918.

En la paciente del caso se refiere un estudio molecular con mutaciones en RET 611 y 620, lo que carece de sentido por las dos mutaciones en un mismo paciente y porque estas mutaciones se asocian con neoplasia endocrina múltiple 2A y carcinoma medular de tiroides familiar. Estos tipos no tienen el fenotipo de la paciente, con eversión de párpados, neuromas mucosos y linguales, alteración en ambos lóbulos tiroideos por ultrasonido y la elevación de calcitonina prequirúrgica (109 normal 0-32) se sospechó carcinoma medular de tiroides. La calcitonina es producida por células $\mathrm{C}$ o parafoliculares y se considera un marcador pronóstico en este tipo de cáncer, por lo que al haber disminuido su valor postcirugía a $2 \mathrm{pg} / \mathrm{mL}$ se considera de buen pronóstico.

En la actualidad, la determinación de metanefrinas descarta la coexistencia de feocromocitoma, aunque esta neoplasia es más frecuente a partir de la tercera década de vida.

\section{REFERENCIAS}

1. Stefan Gfroerer, Udo Rolle. Pediatric intestinal motility disorders. World J Gastroenterol 2015; 21(33): 9683-87.

2. Smith VV, Eng C, Milla PJ. Intestinal ganglioneuromatosis and multiple endocrine neoplasia type 2B: implications for treatment. Gut 1999;45:143-46.

3. Matews MAB, Adler BH, Arnold MA, et al. Difusse intestinal ganglioneuromatosis in a child. J Pediatr Surg. 2013 May; 48(5): 1129-1133. doi: 10.1016/j.jpedsurg.2013.03.066

4. J. Aidan Carney y col. Alimentary-tract ganglioneuromatosis. A mayor component of the syndrome of multiple endocrine neoplasia, type 2B. N England J Med 1976;295(23): 1287-91. 